\title{
POBREZA Y ACCESO AL EMPLEO EN ARGENTINA ¿COMO SE RELACIONAN DEMANDA E INCLUSIÓN LABORAL?
}

\author{
POVERTY AND ACCESS TO EMPLOYMENT IN ARGENTINA \\ HOW ARE LABOR DEMAND AND INCLUSION RELATED?
}

\author{
María Eugenia Sconfienza*
}

RESUMEN

\begin{abstract}
La presente investigación analiza la relación que se establece entre demandantes de empleo y trabajadores pertenecientes a los segmentos más vulnerables en términos socioeconómicos en la Argentina reciente (2004-2016), a la vez que esgrime una síntesis de las principales políticas activas de mercado de trabajo recientes del país. Algunos de los principales hallazgos dan muestra de que existen barreras de acceso a los empleos que operan en detrimento del ingreso al mercado de trabajo y que muchas veces suelen no estar en concordancia a las tareas a ejercer, como son la edad y el nivel educativo.
\end{abstract}

PALABRAS CLAVE: EMPLEO * EXCLUSIÓN * CONDICIONES DE EMPLEO * DESEMPLEO * POBREZA

\section{ABSTRACT}

The research presented an study into the relationship established between jobseekers and workers belonging to the segments of greatest socio-economic vulnerability in recent years in Argentina (2004-2016), while presenting a synthesis of the country's main active labor market policies. Some of the main findings show that in Argentina there are thresholds for access to jobs that are often not in accordance with the tasks to be performed such as maximum age and educational level.

KEYWORDS: EMPLOYMENT *EXCLUSION * CONDITIONS OF EMPLOYMENT * UNEMPLOYMENT * POVERTY

* Centro de Investigaciones Laborales del Consejo Nacional de Investigaciones Científicas y Técnicas, Argentina.

eugeniasconfienza@gmail.com 


\section{INTRODUCCIÓN}

El mercado de trabajo condensa una serie de relaciones en su interior en las cuales persiste una lógica de acceso desigual, es decir, una dinámica en la que la oferta de trabajadores excede el volumen de la demanda laboral y por lo tanto, una parte del universo de trabajadores permanece al margen del empleo. En este sentido, se busca analizar los argumentos que condicionan el acceso al empleo de ciertos segmentos.

La existencia $y$ la perdurabilidad de un mercado de trabajo justo, equitativo y seguro depende de la sostenibilidad en el tiempo de un constante desarrollo económico que respalde la generación de empleos de calidad en cantidad suficiente para absorber la oferta laboral existente (personas trabajadoras dispuestas a trabajar) y que a la vez, permita cubrir las expectativas por parte de la demanda de empleo (empleadores $y$ empleadoras). Asimismo, depende en forma directa de un elevado nivel de actividad que propicie la inversión y que prevea crecimiento en el corto, mediano $y$ largo plazo.

No obstante, en las economías en desarrollo, los escenarios laborales poco tienen de justos, equitativos y seguros. Estos países generalmente presentan un mercado laboral caracterizado por elevados índices de no registro laboral y elevadas tasas de desempleo. En estos contextos, el volumen y la velocidad de generación de puestos de trabajo no resultan suficientes para incorporar a la totalidad de la fuerza de trabajo disponible o potencialmente disponible.

Cuando ello ocurre, en ocasiones el argumento imperante para explicar la marginación de algunos colectivos al mercado de trabajo es la inadecuación de competencias laborales por parte de la población trabajadora. A partir de esto, se desprende que una mejora en la educación, resolvería el acceso al empleo y permitiría acceder al tan deseado "pleno empleo". Pero, la realidad es algo más compleja.

Si las credenciales educativas de la población trabajadora fueran altas, el problema del acceso al empleo persistiría debido a que no se crean puestos de trabajo en el mismo volumen y velocidad que la oferta disponible. Entonces, en este artículo la intención es primero describir y luego plantear hasta qué punto la educación u otros argumentos imperantes en la explicación de la marginalidad no constituyen la pintura que maquilla una situación desigual en la que contribuye la proliferación de estigmas que la sociedad en su conjunto crea, fortalece y transmite.

Consecuentemente, en contextos como el argentino, cabe preguntarse si la proliferación de algunos "filtros" no sería el factor que estaría explicando parte de la exclusión laboral independientemente de la calificación de la persona trabajadora, siendo que la demanda resulta incapaz de absorber a la totalidad de la fuerza de trabajo disponible. Ello no implica despreciar el rol integrador de la educación y el efecto tanto en el desarrollo personal como laboral en las personas de las formación, pero sí matizar la explicación en relación al por qué de la exclusión laboral de algunos segmentos independientemente de sus intenciones de acceso al empleo, no logran la inserción laboral en general, y estable $y$ formal en particular.

\section{EMPLEO Y EXCLUSIÓN EN ARGENTINA}

Exclusión e informalidad no son sinónimos, aunque generalmente se implican mutuamente. Si bien en el caso argentino, no es posible afirmar que todos los trabajadores informales son pobres, una parte considerable de los ocupados de hogares pobres revisten el carácter de no registro ${ }^{1}$. Es por ello que vale decir que el mercado de trabajo en Argentina no escapa a la lógica de "dualismo" en la cual un fragmento "primario" conformado por personas trabajando en un empleo formal relativamente estable, con mejores salarios y cierto nivel de cobertura social (obra social, futuros beneficios previsionales, etc.) se contrapone a un grupo "secundario" de personas trabajadoras en condiciones precarias, en quienes el

$1 \quad$ Al respecto véase para el caso argentino el análisis de Groisman y Beccaria (2008). 
empleo es un bien preciado y escaso. Este sector percibe ingresos más bajos, intermitentes que no permiten la previsibilidad de ingresos futuros y se encuentra excluido de los beneficios de protección social típicamente asociados al empleo ${ }^{2}$.

En estos mercados segmentados donde prevalecen amplios sectores de trabajadores $y$ trabajadoras de bajos recursos, es que la informalidad y la exclusión se presentan como situaciones persistentes. El propósito de este documento es exponer algunos causales que estarían incidiendo en el fenómeno de exclusión y precarización laboral en Argentina. Ello se lleva a cabo desde una perspectiva que, independientemente de las caracterizaciones socioeconómicas de los sectores excluidos más típicas, enfatiza en la incidencia del accionar de la demanda laboral.

Uno de los ejes de este documento radica en la centralidad del trabajo para las personas y los efectos, por tanto, que se derivan de su ausencia. Paugam (1997) entiende que es en el ámbito del mercado de trabajo, que el trabajador logra una identidad y construye un sentimiento de utilidad social, según las funciones que cumple en la división técnica $y$ social del trabajo, repercutiendo sobre su salud. En relación a este último aspecto, varias investigaciones dan muestra acerca de la incidencia de la situación ocupacional en la condición de salud de las personas, coincidiendo en que la situación de desocupación afecta su salud integral y mental (Escarabajal y Rus, 2013; Orellano, 2005; Tefft, 2011; y Vilaseca, 2007).

Por su parte y en sintonía con la argumentación precedente, Castel (1997) destaca que mayores son los riesgos de rupturas sociales y familiares, reducción de la sociabilidad, pérdida de identidad, sufrimiento psíquico y mental, empobrecimiento de los ingresos, cuanto más significativa es la precariedad de la situación de la persona respecto del empleo y por tanto, mayor el deterioro de las condiciones de vida. En este sentido, a medida

2 Estas conceptualizaciones pueden encontrarse en los postulados de Piore (1978 y 1983). que se perpetúan las manifestaciones de precariedad laboral, mayores las probabilidades de profundizar y reforzar la situación de exclusión. Trabajar en condición de "no registro" conlleva relaciones laborales frágiles que, así como el desempleo, implican que la identidad del trabajador es vulnerada porque se siente desvalorizado, se autoculpabiliza $y$ surge un sentimiento de inutilidad $y$ miedo respecto del futuro, dado que derechos laborales y sociales se encuentran vinculados directamente con el empleo ${ }^{3}$.

Los datos para Argentina evidencian un período de mejoras a partir de la superación de la crisis (2001/2002). La pobreza disminuyó en forma marcada desde la salida de la convertibilidad en 2002 y ello fue manifestación directa de una fuerte creación de empleo y de una mejora en los ingresos reales de la población trabajadora. Es posible observar un período de fuerte registración acontecido entre 2006 y 2008 con incrementos entre 3 y 4 puntos porcentuales interanuales. A excepción de 2011 y 2014, con incrementos en la registración leves de 2 y 1,3 p.p. interanuales, el resto del período se mostró amesetado (cuadro 1). Ello evidencia que el escenario laboral argentino continúa teniendo como protagonista a la informalidad, con un tercio de la fuerza de trabajo en situación vulnerable y precaria que, como se demuestra en el cuadro 1, recae en forma más intensa sobre aquellos segmentos de menores niveles educativos.

3 En este documento, se considera como definición de empleo informal, aquel que carece de un registro formal. Para una descripción ampliada y más detallada del concepto de informalidad, véase Sconfienza, apartado 1.1.3 (2012). 


\section{CUADRO 1 \\ PORCENTAJE DE ASALARIADOS CON 18 AÑOS O MÁS \\ SEGÚN CONDICIÓN DE REGISTRO \\ 2004-2016}

\begin{tabular}{lccccccccccccc}
\hline & 2004 & 2005 & 2006 & 2007 & 2008 & 2009 & 2010 & 2011 & 2012 & 2013 & 2014 & 2015 & 2016 \\
\hline $\begin{array}{l}\text { Personas } \\
\begin{array}{l}\text { Asalariadas } \\
\text { Registradas }\end{array}\end{array}$ & 53,0 & 53,8 & 57,3 & 60,3 & 64,4 & 64,8 & 63,9 & 65,9 & 66,2 & 65,9 & 67,2 & 67,4 & 67,0 \\
$\begin{array}{l}\text { Personas } \\
\text { Asalariadas no } \\
\text { Registradas }\end{array}$ & 47,0 & 46,2 & 42,7 & 39,7 & 35,6 & 35,2 & 36,1 & 34,1 & 33,8 & 34,1 & 32,8 & 32,6 & 33,0 \\
\hline TOTAL & 100 & 100 & 100 & 100 & 100 & 100 & 100 & 100 & 100 & 100 & 100 & 100 & 100 \\
\hline
\end{tabular}

Fuente: Elaboración propia con base en la Encuesta Permanente de Hogares del Instituto Nacional de Estadísticas y Censos. EPH-Indec (II trimestres).

En relación a la educación, esta se proyecta en la realidad de la población trabajadora, fragmentando la estructura laboral dado que en forma clara, un mayor nivel educativo corresponde con el nivel de registración. Aquellos con menor nivel educativo presentan mayores niveles de no registro, mientras que quienes tienen mayores niveles educativos son mayoritariamente registrados. Si bien, en términos comparativos, en 2016 respecto al 2004, de acuerdo al total de población asalariada de muy baja calificación (sin instrucción y hasta primaria incompleta) la no registración perdió terreno, pasando de un $74,5 \%$ a un $56,9 \%$, no obstante, implica a más de la mitad de los trabajadores de baja calificación.

Otro rasgo que prevaleció en el período fue una elevada inestabilidad laboral (Groisman, 2010). La significativa proporción de empleos precarizados en la estructura de trabajos conlleva una recurrente rotación laboral consecuencia de un mercado laboral que se presenta como inestable para un segmento de la población. Si bien, este fue un rasgo que se extendió en forma muy marcada en la sociedad argentina durante el decenio de los 90, especialmente en la segunda mitad (Groisman y Beccaria, 2009), en los años que siguieron al 2001 continuó con una intensidad menor, pero se puede afirmar que siguió afectando especialmente a los hogares de menores recursos.
Dentro de la heterogeneidad de la estructura productiva del país, ciertos rasgos característicos son compartidos al interior de las actividades que presentan mayor precariedad (servicio doméstico, construcción, cuentapropismo no profesional, servicios y comercio minorista principalmente) en antagonismo con quienes detentan puestos de empleo estables $y$ registrados. En este sentido, gran parte de las ocupaciones informales representan actividades de refugio, es decir, estrategias de subsistencia para grupos que pueden ser entendidos como marginales concentrando actividades precarias $y$ generalmente fuera de la normativa laboral.

Respecto a la exclusión en Argentina, en el primer trimestre de 2017, la tasa de desempleo se ubicó en 9,2\% y en 6,6\% de desocupación demandante, lo que asciende a más de $15 \%$ de población activa en situación de precariedad. Asimismo, si se considera el contingente de población adulta inactiva con edades entre 18 y 59 años que no está jubilada, rentistas ni estudiantes, este grupo de personas "desalentadas" implicaba para el año 2012, un $11,7 \%$ de la población total (Sconfienza y Groisman, 2015) .

4 Estos no son considerados parte de la Población Económicamente Activa (PEA) dado que no buscaron empleo en los últimos 30 días porque se cansaron de hacerlo, consideraron que no iban a encontrar $\mathrm{u}$ otras razones. 
Teniendo en cuenta estas cifras, a partir de las cuales un segmento no despreciable en términos de volumen está excluido del mercado de trabajo o incluido de forma precaria, en lo que sigue, se pretende arrojar luz en relación a los mecanismos que operarían en la inclusión/ exclusión de ciertos colectivos de trabajadores y trabajadoras según argumentos esgrimidos por demandantes de empleo. Se trata de una indagación acerca de la incidencia de la demanda de empleo en relación a la inclusión laboral.

Vale aclarar que en Argentina, el tamaño del establecimiento incide en la proliferación de empleos protegidos vs desprotegidos. En promedio, entre los años 2004 y 2016, del total de personas asalariadas, el $22,7 \%$ de los puestos de trabajo se concentran en compañías de hasta 5 ocupados; el 36,3\% en medianas empresas de entre 6 y 40 ocupados; $y$ el $41 \%$ se distribuye en establecimientos de 41 ocupados o más; pero al observar la distribución al interior de cada segmento, la mayor parte del no registro se concentra en pequeñas y medianas empresas con un $67,3 \%$ y $27,5 \%$ respectivamente, para el año $2016^{5}$.

Ahora, si bien en las grandes compañías (de más de 40 ocupados) el no registro representa una proporción de carácter más marginal (7,6\% para 2017), lo que suele suceder es que sí persisten barreras de exclusión. Es decir, las pequeñas $y$ medianas empresas son protagonistas en la no registración y secundarias en las exclusión (con barreras más laxas de acceso), mientras que las grandes compañías se erigen como protagonistas de situaciones de exclusión como se describirá más adelante y actrices secundarias en términos de no registración.

Si se incluye a la teoría que el ingreso al mercado de trabajo se correlaciona en forma directa con el nivel educativo, se estaría despreciando el peso de otros factores para el ingreso al mercado laboral que detentan un rol significativo y que condicionan a la población trabajadora como: segregación residencial, edad, condiciones económicas, estigmatizaciones $y$ "filtros" varios por parte de la demanda que

$5 \quad$ Elaboración propia con base en EPH, Indec 20042016 (II trimestres). refuerzan la condición de exclusión en un mercado que imposibilitado para absorber a la totalidad de fuerza de trabajo, tamiza la demanda perjudicando a los segmentos tradicionalmente postergados en su inclusión sociolaboral.

\section{EL ROL DE LA DEMANDA EN LA SEGMENTACIÓN}

A continuación, se desarrollan los resultados de una indagación cualitativa efectuada a partir de diversas fuentes documentales $y$ entrevistas a informantes calificados explorando principalmente tres ejes temáticos involucrados en la decisión de contratar trabajadores: a) los mecanismos de reclutamiento y b) las modalidades de contratación preponderantes utilizadas por las unidades de trabajo, así como algunas valoraciones protagonistas (poco exploradas usualmente) en las decisiones de incorporar personal.

El diseño metodológico incorpora indagación cualitativa con diversos componentes entre los que cabe señalar la revisión documental, la realización de entrevistas en profundidad, la implementación de encuestas y el análisis normativo de diversos mecanismos bajo los cuales se suelen contratar personal en el país.

El diseño de investigación cubrió los tres grandes actores que conforman el grueso de la demanda de empleo en el ámbito privado: grandes compañías consultoras de recursos humanos; pequeñas y medianas empresas ${ }^{6}$; $y$ contrataciones por parte de particulares - estos últimos se constituyen en empleadores al momento de seleccionar por ejemplo, trabajadores de servicio doméstico, mantenimiento y reparaciones domiciliarias (electricista, plomero, albañil, pintor, etc.), entre otras-.

El relevamiento de información se llevó a cabo en el transcurso del año 2013. Este implicó el uso intensivo de diversas fuentes de información cualitativa: entrevistas en profundidad con

$\overline{6} \quad$ Se consideran pymes a aquellas empresas en las cuales el nivel máximo de valor de las ventas totales anuales no supere los siguientes montos por sector en pesos argentinos (ARS): \$54.000.000 (agropecuario), $\$ 183.000 .000$ (industria y minería), $\$ 250.000 .000$ (comercio), \$63.000.000 servicios) y $\$ 84.000 .000$ (construcción). Resolución $\mathrm{N}^{\circ} 50 / 2013$ (www.industria.gob.ar). 
referentes de grandes empresas, organismos vinculados a las pymes y consultoras de recursos humanos; encuestas a particulares acerca de las características de las contrataciones en sus hogares/negocios; asimismo, se utilizó información documental proveniente de otras fuentes como reportes de compañías?

Para el caso de las entrevistas en profundidad, la selección de los casos respetó que se tratara de unidades económicas que poseen presencia en todo el territorio nacional, con dotación de personal superior a 5000 ocupados $y$ con estructuras ocupacionales que en una proporción significativa alberguen empleados en la categoría de operarios ${ }^{8}$. De este modo se trabajó con ocho compañías de vasto reconocimiento en diversas ramas de actividad. Las entrevistas fueron de carácter semiestructurado $y$ se les aplicaron a personal de alta jerarquía del área de recursos humanos ${ }^{9}$.

También, se realizaron entrevistas en profundidad a responsables y técnicos de asociaciones de pymes. Se trata de tres organismos empresariales importantes en la actividad

$7 \quad$ Con la información recolectada vía entrevistas se realizó un trabajo de transcripción en base a los testimonios relevados a partir de las cintas grabadas en audio y posteriormente, se procesó con el programa Atlas ti 6.2. Los datos recolectados se examinaron con el software estadístico de análisis cualitativo mencionado, logrando la organización de la información en redes semánticas identificando categorías y relaciones existentes entre ellas.

Sobre esa base, la descripción y análisis de las particularidades de la demanda de empleo aquí consideradas refieren a los puestos de trabajo de menor calificación y por consiguiente afectan preferencialmente al conjunto de la población de menores recursos socioeconómicos. A modo de referencia, el análisis comprende a la demanda de empleo para aquellos puestos de trabajo que corresponden a las categorías 4 a 9 de la Clasificación Internacional Uniforme de Ocupaciones cIUO de la OIT (OIT, 2008). Esto es, "4" Personal de apoyo administrativo, "5" Trabajadores de los servicios $y$ vendedores de comercios $y$ mercados, "6" Agricultores y trabajadores calificados agropecuarios, forestales y pesqueros, "7" Oficiales, operarios y artesanos de artes mecánicas y de otros oficios, "8" Operadores de instalaciones y máquinas y ensambladores y "9" Ocupaciones elementales.

$9 \quad$ En total se realizaron 370 minutos de entrevistas en profundidad y se recolectó información documental de estas entidades. industrial $y$ en el sector de pequeñas $y$ medianas empresas de comercio. Estas entidades reúnen información acerca de las particularidades y características de las pymes en Argentina desde hace varias décadas, dos de ellas hace más de 50 años. Asimismo, se analizaron datos estadísticos e informes elaborados por estas asociaciones.

Otro de los componentes de indagación fueron las entrevistas en profundidad a referentes de consultoras. Se entrevistó a personas de dos de las más grandes consultoras de recursos humanos que ubican anualmente aproximadamente 43000 personas en todo el territorio nacional ${ }^{10}$.

Respecto de las contrataciones particulares, la intención fue conocer los criterios que operan en los hogares al momento de demandar personal que se desempeña como cuentapropia - aquellos que desarrollan su actividad utilizando solo su propio trabajo personal y usando sus propias maquinarias, instalaciones o instrumental (Instituto Nacional de Estadística y Censos, 2003). Básicamente, el relevamiento se orientó en relación a las dinámicas que operan en la contratación de personal dedicado a la reparación y refacción de viviendas particulares/comercios y personal de servicio doméstico.

La metodología consistió en la aplicación de una encuesta de carácter electrónico (vía internet) durante dos semanas (agosto de 2013). De este modo, se dispuso de 80 encuestas respondidas en forma completa y anónima. La intención de utilizar esta metodología de relevamiento fue captar las peculiaridades de aquellos empleos que no se desarrollan en grandes compañías ni en pymes sino "a puertas cerradas".

10 Se obtuvo material impreso de relevancia acerca de las principales tendencias, actividades y estadísticas publicado por las consultoras indagadas e información documental complementaria disponible en sitios de internet. 


\section{MECANISMOS DE RECLUTAMIENTO SEGÚN NIVEL DE CALIFICACIÓN Y TAMAÑO DEL ESTABLECIMIENTO}

Independientemente del motivo que genere la vacante, en esta sección, se enumeran y analizan algunos de los criterios que prevalecen en casi todos los niveles de contratación. Algunos presentan características formales mientras que otros mecanismos de reclutamiento son predominantemente informales.

Se definen como mecanismos de reclutamiento formales a bolsas de empleo, avisos clasificados en medios gráficos, avisos clasificados en portales de internet, recepción abierta $y$ permanente de curriculum vitae por parte de las oficinas de recursos humanos, consultoras de recursos humanos, agencias de empleo y ascensos internos. Por su parte, la categoría de informales describe a aquellas formas que no contemplan una organización sistemática de la información de las vacantes como en el caso de referidos y carteles/posters/ folletos en vidrieras/negocios.

Algunas de las variables que explican la utilización de diversos mecanismos de reclutamiento se explican en función de: a) el nivel educativo requerido para ocupar el puesto vacante, y b) el tamaño del establecimiento de trabajo (medido en cantidad de personas empleadas).

En las grandes compañías, en función del nivel de calificación que requiera el puesto disponible se realiza el contacto con postulantes de diferentes formas. A mayor nivel de calificación, los medios de reclutamiento tienden a ser más selectivos, precisos y acotados, mientras que por el contrario, en el caso de puestos de menor jerarquía se utilizan mecanismos más masivos e inespecíficos.

En el primer caso, se tienden a utilizar estrategias que van desde los portales de empleo de internet como es el caso de ZonaJobs y Bumeran entre muchos otros o redes sociales (particularmente Linkedin y Facebook), a otras como consultoras de recursos humanos, bolsas de empleo (vinculadas o pertenecientes a universidades) $y$ ascensos internos.

Para los puestos de trabajo de los escalafones más bajos, el mecanismo, si bien no exclusivo pero si preponderante, es el de los referidos o "contactos" de quienes ya se encuentran trabajando ${ }^{11}$. Esto no quiere decir que los referidos no constituya una modalidad para puestos de mayor jerarquía, pero lo que usualmente sucede en estos casos, es que las personas que refieren a otras sean empleados o empleadas de la compañía y los que son referidos o referidas, deban transitar el mismo camino en los procesos de selección que aquellos que provienen de otros medios como por ejemplo, consultoras.

En ciertos casos, se utilizan los avisos clasificados. Lo hacemos para puestos muy masivos en donde realmente necesitamos cubrir, no sé, un start up de un call center - como nos pasó- y necesitamos 300 telemarketers, $y$ la verdad es que hay que buscar canales de captación rápidos, de alto impacto y que la gente llegue rápidamente. Pero sino nosotros usamos para perfiles profesionales muchísimo LinkedIn, Facebook, Twitter. O sea, todo lo que son redes sociales, para perfiles administrativos $y$ profesionales son los número uno, digamos. Y para los más standard y posiciones más bajas usamos el resto de los canales de reclutamiento (...) hacemos pegatinas en los postes de los colectivos, ponemos urnas en los supermercados (Testimonio, Consultora de Recursos Humanos, 2013) ${ }^{12}$.

11 Un estudio de caso para la Ciudad de Buenos Aires acerca de las trayectorias ocupacionales de las personas en situación de calle (que habitan en hogares de tránsito y paradores nocturnos) da cuenta que el mecanismo de reclutamiento preponderantemente utilizado por la demanda laboral en segmentos de baja calificación (empleos de subsistencia) es el de "contactos o referidos". Asimismo, en el mismo documento es posible apreciar la incidencia de cuestiones relacionadas a la edad y segregación residencial como determinantes de la empleabilidad de las personas. Para mayor detalle, véase Sconfienza y Groisman (2013a).

12 La información brindada en las entrevistas es de carácter privado y confidencial, por lo cual no se mencionan nombres en el documento. 
Estas ideas presentaban protagonismo en el ideario de Robert Castel (1997), entre otros analistas de la exclusión sociolaboral. Según este pensador, son los "contactos" el medio más frecuentemente exitoso de acceso a los empleos, debido a que la información de puestos vacantes brindada por familiares, amigos y conocidos es determinante, en ocasiones, para la obtención de un trabajo.

Asimismo, los testimonios de funcionarios de las consultoras ratifican que las empresas tienden a priorizar en la selección de personal a aquellas personas trabajadoras sin episodios largos de inactividad o desempleo. Tanto para el caso de las contrataciones por parte de particulares como en el caso de las pymes que requieren bajos niveles de calificación, el relevamiento indica que el "referido" constituye la modalidad más utilizada en estos casos; las agencias de personal eventual también lo son aunque en menor medida, así como, los avisos clasificados en diarios y la exposición de búsquedas en vidrieras/negocios. Por consiguiente, en pequeños establecimientos y hogares prevalecen mecanismos informales.

En general, la pyme no se maneja a través de consultoras, se maneja en forma casi de: 'Che, tenés alguno bueno'. O, pone un aviso en el diario y lo entrevista el dueño. No está acostumbrado o no está dispuesto a pagar el costo que cobra una consultora en búsqueda del personal (...) diría que hay muchísima falta de profesionalización en el mercado laboral en cuanto a la toma de personal de una pyme. El dueño de la pyme se basa en su intuición, se basa en cómo le cayó el muchacho o la chica, si le demostró tener conocimientos del área que está pidiendo (Testimonio, Organismo pyme, 2013).

Cuando se trata de hogares particulares prácticamente con exclusividad, el mecanismo utilizado es el de "referidos". En las encuestas a los hogares se les efectuó la siguiente pregunta: "En su hogar al momento de contratar personal para reparaciones/refacciones (albañil, electricista, gasista, pintor, plomero, etc.), ¿cuál es el mecanismo de reclutamiento del personal, dónde busca? Los datos arrojaron que en un $94 \%$ de los casos, las personas contratantes mencionaron frente a esta pregunta - abierta_, guiarse por recomendación o referencia de personas conocidas, familiares $y / 0$ amistades.

Para el caso de las empleadas de servicio doméstico, las preguntas referían por una parte a aquellas que contaban con personal contratado: "Si usted cuenta para las tareas generales del hogar (limpieza, etc.) con la ayuda de una empleada doméstica, ¿cómo la contactó?” y para quienes no "Si tuviera que contratar una persona, cuál sería el mecanismo de reclutamiento, dónde buscaría?", ambas preguntas abiertas. En la segunda pregunta, 93\% mencionó referencias o recomendaciones de conocidos, mientras que en el primer caso, $87 \%$ de las respuestas hicieron mención de algún tipo de referencia, $8 \%$ no recordaban y $5 \%$ otros $^{13}$.

Las respuestas vinculadas a los mecanismos de reclutamiento, en su mayoría tanto para servicio doméstico como para la contratación de cuentapropistas fueron en la línea de las siguientes: "A través de un conocido/ amigo/familiar".

\section{MODALIDADES DE CONTRATACIÓN}

En términos normativos, existen esquemas jurídicos en los que se enmarcan las distintas modalidades de contratación laboral. La Ley $\mathrm{N}^{\circ} 20.744$ (Ley de Contrato de Trabajo) regula el empleo en el ámbito privado. En esta se estipulan la forma típica de contratación (por plazo indeterminado), así como, las modalidades especiales (contrato de trabajo a plazo fijo, de temporada, eventual y de grupo). Ciertas actividades quedan excluidas de esta norma $y$ se regulan por otras leyes. Es el caso de las actividades agrarias $^{14}$ (Ley N. ${ }^{\circ} 26.727$, Ley de Trabajo Agrario) y la construcción (Ley $\mathrm{N}^{\circ} 22.250$,

13 En estos casos influye el tipo de labor, dado que el cuidado de niños, la limpieza o las reparaciones al interior de un hogar implica la ponderación de la confianza de quien ingresa al hogar.

14 Con excepción de las tareas de cosecha y/o empaque de frutas que sí se encuadran en la Ley de Contrato de Trabajo. 
Régimen Legal de Trabajo para el Personal de la Industria de la Construcción).

El ámbito público también se regula por una normativa particular, la Ley $\mathrm{N}^{\circ} 25.164$, Regulación de Empleo Público Nacional y el ámbito de contrataciones de personal en hogares particulares lo hace bajo la norma $\mathrm{N}^{\circ} 26.844$, Régimen Especial de Contrato de Trabajo para el Personal de Casas Particulares.

$\mathrm{Al}$ analizar las modalidades preponderantes de contratación relevadas, en un intento de simplificación exagerada, es posible afirmar que a mayor tamaño del establecimiento, las relaciones laborales en su interior se encuentran más cabalmente comprendidas en las normas de los párrafos precedentes. Sin embargo, cuando se trata de contrataciones efectuadas por particulares y pequeñas empresas, la ilegalidad en términos de no registro tiende a ser la modalidad por la que se rigen muchas de estas relaciones laborales.

\section{GRANDES COMPAÑÍAS}

La mayoría de las relaciones laborales en las grandes empresas se encuentran regidas por contratos a tiempo indeterminado. No obstante, también se registran casos de modalidades contractuales no acordes a la relación trabajadorempleador que se da en la práctica. De modo que, si bien no se incurre en la contratación de empleo no registrado, en ocasiones se utilizan encuadres normativos no apropiados. En general, ello ocurre con el propósito de morigerar costos y responsabilidades laborales; es el caso de la contratación de monotributistas (cuando en realidad se trata de trabajadores que prestan servicios en relación de dependencia) y el de contrataciones vía empresas intermediarias. En relación a este último caso, las modalidades contractuales que se presentan suelen ser mediante la provisión de servicios de personal temporario o eventual; $y$ lo que suele denominarse outsourcing, es decir subcontrataciones en la que el trabajador desarrolla su labor en y para una empresa pero su relación de dependencia se establece con otra.

Cuando las búsquedas de personal no implican una relación de dependencia con respecto de las empresas que realizaron la búsqueda, no se presenta contradicción ni conflicto normativo alguno, ya que la empresa intermediaria, generalmente una consultora de recursos humanos, simplemente brinda el servicio de reclutamiento. Ahora bien, en los casos de contrataciones en las que se trata de actividades tercerizadas, el panorama tiende a tornarse más complejo e impreciso.

Desde comienzos de los 80 , se han reglamentado las actividades de las empresas de servicios eventuales. En sus orígenes, ofrecían personal para el reemplazo de algún trabajador ausente, para que hiciera frente a picos de trabajo ocasionales o a necesidades puntuales $y$ transitorias. Sin embargo, tendieron a cubrir puestos de trabajo de carácter permanentes referidos a tareas propias de la actividad normal de las empresas, constituyendo la nómina del plantel regular y efectiva. De este modo, esta modalidad de contratación pasaba a encubrir períodos de prueba que no estarían autorizados por ley. Ello constituye uno de los motivos por el cual en la actualidad los empleadores $y$ las empleadoras pueden contratar a las empresas de servicios eventuales siempre que se encuentren habilitadas por el Ministerio de Trabajo de la Nación ${ }^{15}$.

De todos modos, persisten situaciones conflictivas dado que tanto el empleo eventual como la subcontratación ofrecen vías indirectas para contratar fuerza de trabajo, reduciendo costos laborales directos e indirectos y por consiguiente, eludiendo en ocasiones el costo real asociado a la seguridad social ${ }^{16}$. Esta utilización por parte de las empresas de fuerza de trabajo contratada y remunerada por contratistas independientes a la empresa, pone a la población trabajadora en situaciones especialmente precarias $y$ al mismo tiempo permite que la persona empleadora auténtica pueda llegar a negar las acusaciones en caso de cese de las actividades o de reconocimiento de los derechos (Magdoff $y$

15 Las empresas de servicios eventuales encuentran reglamentada su actividad en el Decreto $\mathrm{N}^{\circ}$ 1694/2006 P.E.N.

16

Para un mayor desarrollo acerca de las diversas modalidades de subcontrataciones, véase Goldin (2008). 
Magdoff, 2004). Un ejemplo de tercerización lo proporciona la siguiente cita:

Del total de empleados, hay que sumarle 25.000 mil que están en los "call" (center) de terceros. Como no nos da el volumen de atención, hay sectores tanto técnicos como de atención o venta telefónica que los tenemos con terceros (Testimonio, Empresa de telecomunicaciones, 2013).

Las empresas tercerizadas (no eventuales) a su vez pueden efectuar sus contrataciones mediante diversas alternativas: tiempo indeterminado, a plazo fijo, de temporada y eventual en forma directa. Inclusive, pueden incurrir en la contratación de empresas de servicios eventuales, con lo cual existe la probabilidad que una persona trabajadora, por ejemplo de un call center que labora en $y$ para una determinada empresa, se encuentre en relación de dependencia con una agencia eventual, que a su vez fue contratada por una firma tercerizada que a su vez fue contratada por la empresa en la que efectivamente se realiza la labor. Estableciéndose una cadena de intermediarios que puede jugar en contra del cumplimiento pleno de derechos para el trabajador o trabajadora. Tal como sostienen Basualdo, Esponda, Gianibelli y Morales "en la cadena de la tercerización, el eslabón más débil es el trabajador” (2015, p. 8).

Comúnmente, en el resto de los sectores, cuando esto sucede se concentra en tareas como las de administración del comedor, seguridad, personal de maestranza y mantenimiento.

En relación a la contratación vía encuadre normativo como "eventual", la normativa argentina entiende que cuando el personal suministrado por una empresa de este tipo de servicios no presta tareas que revisten la calidad de eventual, tanto la empresa como la agencia de personal incurren en fraude laboral. Por lo tanto, la utilización de esta figura "eventual" debe ser extraordinaria dado que la ley manifiesta la prohibición del uso de estos contratos para cubrir puestos de trabajo permanentes. Del mismo modo, si se utiliza la forma "eventual" como paso intermedio antes de la contratación a tiempo indeterminado también se estaría obrando por fuera de lo dispuesto en la normativa vigente (más allá que la contratación finalmente a plazo indeterminado sea para la agencia o la empresa). En estos casos uno de los efectos colaterales es que se puede llegar a extender el plazo de incertidumbre laboral de la persona trabajadora (más allá de los tres meses de prueba que contempla la norma de contrato a plazo indeterminado).

A fin de año nosotros tenemos que reforzar las líneas de caja, $y$ ahí sí tomamos gente $y$ después si damos de baja porque no los necesitamos (...) ahí es donde nos manejamos con el personal eventual (...) tomamos personal de refuerzo para esa época del año a través de consultoras.

(...) Para las posiciones operativas de tienda, en Buenos Aires, trabajamos con agencias de personal eventual. (...) Durante los primeros tres meses está bajo el contrato de agencia - como eventual $-y$ después pasa directamente a contrato. (...) entran, a los tres meses quedan, si pasan el período de prueba, digamos, quedan en la compañía y ahí sí se los toma directamente por nómina. En el interior es contratación directa, con contrato a prueba (Testimonio, Supermercado, 2013).

La cita precedente muestra el contraste entre una situación de contratación directa (en el interior o resto del país) y la utilización de la figura de eventual antes de la incorporación permanente (en Buenos Aires). Al no existir parámetros preestablecidos que permitan acreditar la adecuación de la categoría de "eventual" de las contrataciones, se observa la naturalización de este tipo de empleo respecto de tareas que no necesariamente califican para tales casos $^{17}$.

$17 \quad$ Al respecto, existen denuncias y propuestas permanentes para limitar la proliferación de estas contrataciones irregulares indirectas. Algunos ejemplos: un proyecto de Ley presentado en marzo de 2015 por el Dr. Recalde propone lo siguiente 


\section{PYMES Y PARTICULARES}

Las pymes reconocen que una parte no despreciable del personal que se desempeña en estos establecimientos lo hace en forma no registrada. Los datos estadísticos del país también lo indican como se mencionó al inicio del documento. Del mismo modo, las personas empleadoras que contratan cuentapropias en sus hogares particulares, también reconocen efectuar acuerdos informales.

El primer argumento que suele señalarse desde el sector de las pymes, es que las cargas sociales constituyen un obstáculo para la contratación de personal. Sin embargo, existen también otros argumentos que suelen estar presentes en los relatos de los referentes pymes. Entre los mencionados con mayor frecuencia se encuentran: estructuras pequeñas e informales en su organización interna, incertidumbre económica, baja productividad, dificultad del acceso a crédito y falta de asesoramiento en las decisiones económicas, entre otras.

De las modalidades de contratación más difundidas en el sector pyme, se destacan aquellas en relación de dependencia "encubierta" bajo la figura del monotributo o aquellas en las cuales el registro laboral es bajo la modalidad de relación de dependencia, como por ejemplo, se declaran menos horas de trabajo que las efectivamente cumplidas por el trabajador; se le categoriza en un rango inferior a pesar de las habilidades y las responsabilidades que corresponden a su puesto o bien, se contempla a los trabajadores bajo una modalidad contractual de "pasante" cuando en realidad no lo son.

"Artículo $1^{\circ}$-Incorpórese como último párrafo del artículo 30 del Régimen de Contrato de Trabajo aprobado por ley 20.744 y sus modificatorias, el siguiente: En los casos en que las tareas o actividades objeto de contratación o subcontratación se realizaran en el establecimiento del principal o en instalaciones que se encuentren bajo su custodia o guarda, en orden a los derechos individuales resultará de aplicación a los trabajadores dependientes del contratista o subcontratista el régimen legal y convencional aplicable en la principal en cuanto resulte más favorable". Disponible en www.hcdn.gob.ar.
En el caso de las contrataciones de servicio doméstico en hogares particulares, las encuestas arrojaron que de 48 casos relevados, 22 tenían a sus empleadas registradas. No obstante, según los datos de la eph, las cifras de no registro oscilan entre el $80 \%$ en el servicio doméstico para el año 2012 (citradis, 2012)18.

Entre las principales explicaciones a la elevada tasa de no registro en el sector, cabe mencionar que esta actividad laboral se realiza a puertas cerradas (dentro de viviendas particulares) y ello dificulta la labor de los organismos de inspección. Por otra parte, la relación entre trabajadora y empleadora puede discrepar (en no pocas ocasiones) del clásico vínculo asalariado-patrón, y no es extraño que ni la trabajadora ni la empleadora se reconozcan integrando una relación laboral (Sconfienza y Groisman, 2014). Ello puede conducir tanto a relaciones de extrema confianza como a actos emparentados con el vasallaje, en los cuales no es recurrente que se plantee la necesidad/obligación de tributar las cargas sociales. Además, operan otros factores que pueden ejercer alguna incidencia también en el elevado nivel de informalidad del sector. Por ejemplo, el hecho de que una proporción elevada de las empleadas domésticas sean migrantes internacionales. Puede estimarse que en el período 2004-2012, una de cada cinco trabajadoras del servicio doméstico que residen en el Gran Buenos Aires proviene mayoritariamente de Paraguay, Perú o Bolivia, en ese orden (Sconfienza y Groisman, 2013b).

Finalmente, otro factor que atenta contra la formalización de las relaciones laborales es la dificultad que enfrentan las asociaciones gremiales o sindicatos del sector para incrementar su representatividad entre las trabajadoras. Consecuentemente, las empleadas domésticas disponen de una escasa capacidad de presión y un débil poder de negociación para exigir el cumplimiento de sus derechos laborales.

18 A partir de esto se deduce que en la encuesta aplicada pueda existir un problema de sesgo, dado que los encuestados vía "online" no conforma una muestra aleatoria, como sí lo son quienes participan de la muestra que utiliza la eph. 
Para el caso de las contrataciones referidas a reparaciones/refacciones al interior de los hogares, en el relevamiento efectuado, ante la pregunta: "conoce la situación ante la AfIP del personal que contrata", $77 \%$ de los casos mencionaron desconocer la situación ante AFIP del personal contratado, mientras que $6 \%$ mencionó conocer que trabajan en forma no registrada (informal).

\section{ARGUMENTOS QUE ASUMEN PROTAGONISMO EN LAS INSTANCIAS DE INCORPORACIÓN: LOS UMBRALES EDUCATIVOS Y ETARIOS}

Los umbrales de acceso al empleo cuando corresponden a la labor a realizar, tienen una razón de ser, entre los que se encuentran, el nivel de conocimiento requerido específico acreditado, ciertas características y estados de salud físicos en el caso de requerir trabajos de fuerza, etc. Ahora bien, existen otros umbrales de acceso que en ocasiones parecieran no estar asociados a las tareas y se interponen en el camino, imposibilitando a los candidatos y las candidatas a "formar la fila" para postularse. Estos umbrales detectados se encuentran constituidos principalmente por la edad y el nivel educativo.

Dinámicas tales se evidencian simplemente al revisar algunos requerimientos en bolsas de empleo diversas. A modo de ejemplo, se revisaron los requerimientos publicados en una bolsa de empleo online de una organización sin fines de lucro que realiza entre otras actividades, intermediación laboral. El análisis permite apreciar que una gran cantidad de las búsquedas muestran la tendencia de las personas empleadoras de ponderar niveles educativos $y$ franjas etarias restringidas que a simple vista parecieran no corresponder con los puestos de trabajo. Algunos ejemplos se citan a continuación ${ }^{19}$ :

19 Es probable que ciertas tareas que parezcan no requerir el nivel medio completo, en la práctica sí lo requieran, dado que deben aplicar conocimientos o habilidades típicamente adquiridas en ese nivel, lo mismo puede suceder con la edad, en el caso que ciertos puestos requieran de aptitudes físicas. No obstante, puede que no sea así, que los requisitos operen simplemente como umbral para limitar la oferta de trabajo que se presente ante las búsquedas en contextos de acotada demanda como el argentino. $\diamond \quad$ Encargado/a de edificio con vivienda/25 a 35 años/ secundario completo

$\diamond \quad$ Vendedor/25 a 45 años/secundario completo

$\diamond \quad$ Empleado de expedición y depósito/25 a 35 años/secundario completo

$\diamond \quad$ Asistente administrativo/20 a 40 años/ secundario completo

$\diamond \quad$ Empleada administrativa/30 a 45 años/ secundario completo

$\diamond \quad$ Vendedor de indumentaria masculina/24 a 35 años/secundario completo

$\diamond \quad$ Cadete/18 a 26 años/secundario completo

$\diamond \quad$ Vendedor/hasta 35 años/secundario completo

$\diamond \quad$ Operario de fotocopiadora/22 a 35 años/ secundario completo

$\diamond \quad$ Boletero/25 a 45 años/secundario completo

$\diamond \quad$ Auxiliar administrativa/22 a 27 años/ secundario completo

$\diamond \quad$ Telemarketer/18 a 30 años/secundario completo

Fuente: publicación online de búsquedas activas durante los meses de abril y mayo de 2014 .

La edad constituye uno de los temas, aunque no siempre analizados con exhaustividad, de mayor protagonismo en las decisiones relativas a la incorporación de personal. Si bien, existen varios documentos que abordan la perspectiva de la población joven y la inclusión laboral, en el caso de los adultos, la disponibilidad de información aún resulta acotada, en particular para Argentina. Como se mencionó, en ocasiones, no es solo el criterio de la edad el que determina la exclusión de oferta de trabajo ante eventuales incorporaciones laborales, sino también el nivel educativo. En aquellos casos en los cuales ciertas tareas no parecieran requerir niveles educativos mínimos, la existencia de umbrales de ingreso como "el nivel secundario completo" parecieran ser simplemente eso, un umbral para limitar la oferta de trabajo que se presenta ante cada nueva búsqueda.

Con base en datos proporcionados por la Encuesta de Demanda Laboral Insatisfecha (DLI) elaborada por el Ministerio de Trabajo, Empleo 
y Seguridad Social de la Nación (que releva aproximadamente 2700 empresas), del total de los puestos demandados -independientemente de haber sido cubiertos o no- en el grupo de operarios para el período 2005-2013, un promedio de $64 \%$ presentaban restricciones en relación a la edad, de los cuales $67 \%$ refieren a búsquedas de menores de 45 años.

A lo largo del trabajo de entrevistas realizadas a referentes del mundo empresario se ha abordado esta temática en forma directa (mediante preguntas que explícitamente referían a la existencia o no de preferencias ligadas a la edad de los candidatos) y de manera indirecta (los entrevistados y las entrevistadas recurrentemente han mencionado la cuestión de la edad). Ante las preguntas referidas a la prevalencia de criterios de preferencia por los jóvenes, en general no se admitió en forma directa, no obstante, con base en la documentación analizada, la gran mayoría de las incorporaciones que realizan las empresas se concentran en este grupo (el grueso de incorporaciones suele estar representado por menores de 30 años de edad). Muestra de ello se hace visible en los reportes sociales anuales publicados por las empresas, en los cuales describen en forma general la caracterización de incorporaciones del año. El 66\% de las incorporaciones del año 2012 declaradas por una empresa de $672 \mathrm{em}-$ pleados (telecomunicaciones) es menor de 30 años; el 59\% de las incorporaciones del año 2012 declaradas por una empresa de 343 empleados (industria alimenticia) es menor de 30 años; y el 86\% de las incorporaciones del año 2011 declaradas por una empresa de 1583 empleados (supermercadismo) es menor de 30 años. Esta última compañía que en 2011 incorporó solo un 14\% mayores a 30 años de edad -según sus propios reportes-, reconoce paradójicamente a través de uno de sus funcionarios entrevistados dificultades asociadas a la alta rotación de los jóvenes ${ }^{20}$ :

20 En un documento del Centro de Estudios e Investigaciones Laborales se menciona en relación a esta temática que "la inestabilidad impacta más sobre los jóvenes, dado que de manera forzada 0 voluntaria rotan entre empresas u organizaciones con mayor frecuencia, porque tienen dudas
Nosotros lo que estamos viendo es que las nuevas generaciones, no tienen el mismo compromiso que tenía gente más grande (...). Nuestra expectativa es que cuide más el trabajo y sea más disciplinado en cuanto al cumplimiento. En el caso de los jóvenes, por ahí, lo que se ve es que ingresan y a los dos o tres días no les gustó algo, lo dejaron y vos lo que invertiste desde todo el proceso de selección, hasta la formación para que pueda ocupar ese puesto, la perdés (Testimonio Empresa de la rama del supermercadismo, 2013) ${ }^{21}$.

Asimismo, las entrevistas permitieron detectar algunos de los argumentos que fundamentan los criterios por los cuales se privilegian a los jóvenes por sobre los adultos: que el empleado pueda crecer en la empresa "promoción interna", "los niveles más operativos,

sobre si reúnen o no las condiciones para ejercer una profesión, permanecer, desarrollarse y hacer carrera en una misma empresa, y porque en el momento de ingresar hay mucha distancia entre sus conocimientos teóricos y los requerimientos operativos del puesto de trabajo. A esto se agrega un cambio cultural, porque así como las empresas no tienen restricciones morales y se desprenden fácilmente de personal cuando creen que eso es necesario para preservar su existencia, los jóvenes van cambiando sus actitudes y comportamientos cuando comprenden la lógica empresarial. Ha disminuido el sentimiento de lealtad $y$ de fidelidad hacia la empresa, una vez que ingresan no se sienten atados a ella para siempre. En condiciones laborales inseguras e inestables, los jóvenes no tienen como antes mayores escrúpulos mientras continúan en el empleo para postularse ante varias empresas y adoptar la decisión final en función de sus intereses, expectativas y motivaciones personales" (Neffa, Oliveri, Persia y Trucco, 2010, p.34).

21 En el año 2016, se le consultó a una cadena de supermercados (retail reconocida mundialmente que opera en Argentina), acerca del éxito de este cambio $y$ la respuesta fue que siendo el segundo año que se implementaba el programa de incorporación de adultos mayores de 40 años (2013 y 2014) les fue "bien" y la mayoría de trabajadores incorporados a través de este programa continúan en sus puestos, pero que aun las cantidades ingresadas eran muy bajas, solo 30 adultos de esta franja etaria cada año. 
administrativos, más bajos naturalmente son cargos junior", "evitamos la sobrecalificación", "las personas grandes tienen vicios laborales". Es posible que esto se encuentre asociado a la búsqueda de mayor flexibilidad por parte de los empleadores, pago de salarios más reducidos y arraigamiento de pensamientos, tales como la menor capacidad de adaptación de las generaciones más adultas.

Si bien, en las entrevistas salieron a la luz argumentos en relación a limitaciones concretas como el dominio de herramientas informáticas que es razonable que pueda interferir en las habilidades de las generaciones de mayor edad, las mayoría de las veces parecieran prevalecer "prejuicios" disimulados bajo lemas tales como "somos una empresa joven".

Las consultoras de recursos humanos reconocen la presencia de estigmas referidos al nivel de compromiso $y$ expectativas laborales según edades.

(A las personas mayores de 40) (...) Los ven como más cansados, más rutinarios quizás más como inflexibles a la hora de tener que readaptarse a situaciones nuevas, a trabajar con gente joven. Estas son las cosas que nos dicen. No lo que yo pienso en absoluto sino esto es lo que nosotros decimos por parte de las empresas. A esto yo llamo vicios, estigmas o cuestiones que muchas veces no son así (...) (Testimonio, Consultora de Recursos Humanos, 2013).

Un relevamiento publicado en 2012 realizado por el Instituto Nacional contra la Discriminación, la Xenofobia y el Racismo (INADI) reveló que de 3668 avisos clasificados relevados de portales de empleo de internet $y$ de avisos clasificados en diarios, un $22 \%$ incluyó límites etarios y un $74 \%$ de esta cifra apunta a personas menores de 40 años, mientras que apenas el $26 \%$ admite que los candidatos y las candidatas superen esa edad ${ }^{22}$.

22 "La discriminación laboral consiste en la vulneración del derecho a acceder a un trabajo a causa de algún tipo de característica personal que nada tiene que ver con la idoneidad que ese
Al dirigir este análisis por fuera del ámbito empresarial, para el caso de personal de servicio doméstico, los datos muestran que no se repite la lógica de discriminación por edad. Según la encuesta aplicada en el presente documento, los porcentajes se distribuyen de la siguiente manera: $21 \%$ de 18 a 30 años; $33 \%$ de 31 a 40 años; 25\% de 41 a 50 años; 17\% de 51 a 60 años y 4\% más de 60 años.

Ahora bien, ¿qué sucede en relación a los requerimientos de escolaridad? Varias de las empresas relevadas dieron cuenta que en general, el primer filtro de los postulantes es vía web. Esto es porque al solicitar la descripción del nivel educativo obtenido se van quedando "afuera" aquellos que no cumplen con este mínimo. Si los puestos que se buscan son de baja calificación, es probable que el aspirante no disponga de medios electrónicos para conocer las ofertas de trabajo y por tanto para postularse. De este modo, en estos casos los avisos vía web estarían operando como un triple umbral de ingreso. En primer lugar, el acceso a internet $y$ el dominio de herramientas informáticas para buscar y aplicar a vacantes; en segundo lugar, el filtro de la edad, ya que en muchas ocasiones aquellos de más edad disponen de conocimientos más acotados sobre estas herramientas; $y$ en tercer lugar, el nivel educativo que se declare en caso de enviar solicitudes vía internet.

Se debe considerar que según los datos proporcionados por el Censo 2010, 47\% de la población no utiliza la computadora, $55,5 \%$ de la población entre 15 y 59 años de edad no finalizó sus estudios secundarios, de la cual 20,5\% no asistió a un establecimiento educativo y

puesto requiere. Este tipo de práctica, cabe destacar, incluye tanto la etapa previa a la contratación como el efectivo vínculo laboral. (...) el lugar de trabajo es el segundo ámbito en donde se sufren con mayor frecuencia prácticas discriminatorias, especialmente aquellas relacionadas con el nivel socioeconómico, la nacionalidad, el género, la edad y otras características personales que no "encajan" con los paradigmas. (...) de igual modo, este ámbito (laboral) es identificado como el más discriminatorio para las personas mayores de 60 años. (...) muchas personas siguen asociando a esta población como poco productiva y, sobre esta base, es negado su acceso al trabajo" (INADI, 2014, p. 88). 
$35 \%$ lo hizo pero sin finalizar la escuela media. Aunque para ciertas tareas no es necesario el nivel medio completo, para la gran mayoría de puestos de trabajo de baja calificación sí se exige este requisito.

(...) para niveles de operadores o vendedores, que es el ingreso de menor 'seniority' en la organización, sí exigimos que todos tengan secundario, digamos como requisito para ingresar a la compañía (Testimonio, Compañía de bebidas, 2013).

Hay un pre-requisito previo, tiene que tener el secundario terminado. No puede entrar nadie sin el secundario terminado. Eso es como un pre-requisito (...) cualquiera sea al puesto (...) (Testimonio, Supermercado, 2013).

(...) el que tiene secundario completo siempre va a prevalecer sobre aquel que no tiene estudios (Testimonio, Consultora de Recursos Humanos, 2013).

Entre los argumentos mayormente esgrimidos por los funcionarios y las funcionarias de las áreas de recursos humanos de las compañías indagadas, aquellos mencionados con mayor frecuencia que justifican esta restricción son: el manejo de maquinarias, la presentación de informes regulares y el dominio básico de herramientas informáticas. Sin embargo, se detectó que cuando las fábricas/plantas se encuentran alejadas de los centros urbanos, la disponibilidad de personal para tareas más básicas con nivel secundario completo y edades más jóvenes se reduce. Por consiguiente, en estos casos las empresas tienden a incorporar personal independientemente de su nivel educativo $y$ de la edad.

Los testimonios evidenciaron que para el caso de empresas con presencia en localidades pequeñas del interior del país, el promedio de años de antigüedad de las personas empleadas (y por tanto de las edades medias) tiende a ser superior que en el caso de las grandes urbes, evidenciando menor rotación (siempre que no se trate de tareas vinculadas al campo), así como, los niveles de educación requeridos para cubrir las vacantes suelen ser inferiores. Situación que no ocurre en las proximidades a centros urbanos donde la oferta de trabajo disponible suele ser mayor ¿Qué estaría indicando esta dinámica? Es posible pensar que la restricción del nivel medio, así como, las edades máximas cuando la tarea no lo requiere en forma determinante, obedezcan a la realidad de limitar a los postulantes por un desajuste entre una oferta laboral considerablemente superior a la demanda disponible del lugar.

Un estudio publicado por Neffa y Korinfeld en 2006, acerca de la composición de la demanda de empleo en empresas de servicios eventuales en Argentina, indica que tanto para los puestos de operarios como administrativos, vendedores $y$ promotores es requisito mínimo el nivel secundario de educación. Aunado a lo anterior, un estudio realizado el mismo año por la Universidad de General Sarmiento (Groisman, Beccaria, Maurizio y Gonzalez, 2006) en relación al nivel de adecuación de las demandas de credenciales educativas que las firmas establecen para cubrir sus puestos de trabajo en la Provincia de Buenos Aires, determinó que en el $20 \%$ de los casos de los puestos de trabajo analizados, las credenciales educativas demandadas por las empresas sobrepasaban los requerimientos que tendría el puesto de trabajo.

Por su parte, para los casos de contrataciones en hogares particulares, el nivel educativo no se manifestó como un aspecto que tuviera algún impacto en la decisión de contratar tanto empleadas del servicio doméstico como cuentapropistas para refacciones y afines.

En resumen, tanto nivel educativo como edades máximas, constituyen barreras de acceso al empleo determinadas por parte de la demanda laboral (grandes compañías) que contribuyen a la "exclusión".

POLÍTICAS ACTIVAS DE EMPLEO EN ARGENTINA: CUATRO ESTRATEGIAS DE INTERVENCIÓN

Debido a los efectos arrastrados luego de la crisis económica acontecida en el país en los años 2001 y 2002, entre 2004 y 2012, se han 
implementado diversas acciones con el propósito de ampliar la protección social, siendo la Asignación Universal por Hijo y las moratorias previsionales ejemplos destacables debido a su gran cobertura ${ }^{23}$. Si bien no existen datos específicos del grado de cobertura de los diversos programas, una publicación del Ministerio de Trabajo refleja las siguientes cifras de beneficiarios: 1919919 (2004), 1747455 (2005), 1527 691 (2006), 1183301 (2007), 987779 (2008), 1 017571 (2009), 548140 (2010) y 516839 (2011), 364817 (enero a mayo de 2012) —cabe aclarar que no se especifica el nombre de los programas contabilizados- (мтеyss, 2012).

Algunas de las principales políticas de mercado de trabajo activas nacionales orientadas a segmentos desfavorecidos en el período 2004-2012 se resumen a continuación:

a) El Programa de Recuperación Productiva "REPro" (2002) bajo la órbita del mTEyss (subsidio destinado a solventar parte del salario de las personas trabajadoras durante un tiempo determinado, destinado a trabajadores en general y empresas en situación de crisis).

b) El Plan de Desarrollo Local y Economía Social "Manos a la Obra" (2003) del Ministerio de Desarrollo Social de la Nación (мDs) destinado a proporcionar apoyo económico y técnico a iniciativas de emprendimientos productivos presentados a través de ong's, comunas o municipios para trabajadores desocupados y familias en situación de vulnerabilidad.

c) El Plan Integral para la Promoción del Empleo "Más y Mejor Trabajo" (2003) del мтEyss, destinado a desarrollar capacidades y competencias para mejorar las condiciones de empleabilidad de la población trabajadora desocupada.

d) El Plan Nacional de Regularización del Registro Laboral (2004) del mTEyss con el propósito de intensificar las acciones de

23 Para un detalle en profundidad de algunos de los programas más destacables en materia de empleo en relación a sus características e impacto, véase CEIL, 2011. inspección laboral para el conjunto de personas trabajadoras no registradas.

e) El Programa de Inserción Laboral (2006) ejecutado por el мтEyss con el fin de favorecer el autoempleo para el colectivo de personas trabajadoras desocupadas y empresas mediante el ahorro de contribuciones patronales.

f) El Seguro de Capacitación y Empleo en 2006, dependiente del mтEyss para apoyar la búsqueda de empleo, orientación laboral, actualización de competencias laborales e inserción al empleo mediante la intermediación laboral con empresas demandantes.

g) La creación de la Red de Oficinas de Empleo en 2006 por parte del мтеyss para facilitar la inclusión sociolaboral y promover el acceso a oportunidades de empleo registrado a la población trabajadora desocupada perteneciente a grupos vulnerables.

h) El Plan Jóvenes con "Más y Mejor Trabajo" en 2008, a través del cual el мтеуss buscaba mejorar la empleabilidad de la población joven mediante cursos de formación profesional y estrategias de intermediación laboral con demandantes de empleo locales destinado en particular a personas entre 18 y 24 años sin estudios obligatorios completos.

i) El Programa Ingreso Social con Trabajo en 2009 del mDs, con el propósito de generar empleo a través de cooperativas de trabajo encargadas de ejecutar obras de infraestructura local.

j) El Plan "Argentina Trabaja" del mDs, que buscaba promover la creación de cooperativas $y$ otros grupos asociativos mediante capacitación, créditos y colaboración técnica para fortalecer el desarrollo local y la generación de puestos laborales para personas desocupadas y familias en situación de vulnerabilidad ${ }^{24}$.

Los programas implementados dan cuenta de una incorporación a la agenda pública en forma clara de la problemática de la

24 
exclusión laboral, así como de gran cantidad de programas asistenciales que se desarrollaron en el período, complementados por estrategias de intervención en el campo laboral para el universo de los segmentos más precarizados. Una tipificación de estas intervenciones permite dar cuenta que las acciones implementadas giraron mayoritariamente en torno a cuatro pilares fundamentales:

$\begin{array}{ll}\diamond & \text { Generación de empleos } \\ \diamond & \text { Subsidios al salario } \\ \diamond & \text { Capacitación } \\ \diamond & \text { Intermediación laboral }\end{array}$

\section{GENERACIÓN DE EMPLEOS}

La creación de puestos de trabajo se llevó a cabo básicamente mediante el apoyo técnico y económico para la generación de autoemprendimientos productivos individuales $y / 0$ cooperativas $^{25}$. Si bien no es posible contabilizar las cifras de los empleos creados mediante esta vía de intervención, la incidencia fue moderada. Por un lado, no se registran políticas crediticias para empresas grandes o pymes, lo que derivaría más probable y directamente en generación de empleos. Por el otro, el empleo que se creó tendió a ser informal dado que si bien se instituyó para este tipo de inserciones laborales un instrumento denominado "monotributo social", este no tuvo la efectividad suficiente para excluir a los trabajadores y las trabajadoras de prácticas laborales precarias ${ }^{26}$.

25 Una cooperativa se define como una asociación autónoma de personas unidas voluntariamente para satisfacer sus necesidades $y$ aspiraciones económicas, sociales y culturales en común a través de una empresa de propiedad conjunta y de gestión democrática (OIT, 2002).

26 El monotributo social es un régimen específico derivado del monotributo, para aquellas personas en condiciones de vulnerabilidad social, debidamente acreditadas, que se encuentren en situación de desempleo o que resulten real o potencialmente beneficiarias de programas sociales o de ingreso; también para aquellas personas jurídicas cuyos integrantes reúnan las condiciones anteriormente descritas 0 aquellas que pudieran ser destinatarias de programas sociales o de ingreso (MTEyss-OIT, 2007).
Los principales logros de estas intervenciones están asociados a la inclusión en el mercado de trabajo formal de trabajadores y trabajadoras por cuenta propia vulnerables e históricamente excluidos. En el año 2011, se registraron inscriptos cerca de 450000 monotributistas sociales $^{27}$ (Calero, 2012). No obstante, el monotributo social no deja de representar una modalidad de precarización laboral, que muy lejos se halla de alcanzar los estándares mínimos de seguridad y calidad en las prestaciones de los que goza un empleo asalariado y registrado. Además, numerosas veces se da un cese en el pago del tributo que lleva a los trabajadores nuevamente a una situación de desprotección.

Por otro lado, la generación de cooperativas, que si bien implica una modalidad contractual en la cual no hay trabajadores/patrones, suele caracterizarse por algunas dificultades como la falta de conocimiento de las personas trabajadoras en relación a la gestión/inversión comercial. Además, la falta de inversión sumada al cese de colaboración estatal en la compra de insumos o herramientas de trabajo pueden propiciar el fracaso. Otra de las características que suele atentar contra el éxito y la proliferación de las cooperativas, es que al ser promovidas por el Estado ${ }^{28}$, en ocasiones pueden llevar al desconocimiento para encarar una trayectoria de inversión y crecimiento ${ }^{29}$, derivándose en su desintegración o suspensión de actividades.

\section{SUBSIDIOS AL SALARIO}

Es conocida la demanda constante por parte del sector privado que busca presionar sobre el "costo laboral". Sin embargo, atender a estas presiones muchas veces puede conducir en extremo a fomentar la "precarización" de la fuerza laboral. Los programas que promueven

$27 \quad$ La cifra corresponde al acumulado de inscriptos entre 2006 y 2011, lo que no implica la permanencia en la categoría del total.

28 Principalmente a través del Instituto Nacional de Asociativismo y Economía Social (INAEs) dependiente del MDS.

29 Para un análisis acerca de las deficiencias aun presentes en las estructuras cooperativas argentinas, véase Basañes (2010). 
subsidios al salario, constituyen una herramienta que tiende a favorecer la contratación principalmente en aquellos establecimientos de baja productividad. En general, está medida en la práctica presenta mayor incidencia sobre el registro de población trabajadora no registrada que sobre la contratación de nuevos trabajadores y trabajadoras.

El alcance del Programa de Recuperación Productiva (REPRo) fue significativo en sus inicios (2003), prácticamente marginal en el período 2004-2007 y hacia fines de 2008 (período en que la economía local hace eco de la crisis internacional) comienza a incrementarse el número de adhesiones significativamente. En el año 2009, se llegaron a registrar 143000 personas trabajadoras pertenecientes a un total de 2769 establecimientos, de los cuales el $77 \%$ son pequeñas y medianas empresas de menos de 50 empleados (мтеyss, 2010).

Aunque el gobierno no busca reducir en forma directa los costos laborales porque entiende que es una forma de fomentar la precarización de la persona trabajadora, sí reconoce en diversos documentos que las personas empleadoras tienden a recurrir a estrategias fraudulentas de contratación. En el caso de las pequeñas empresas, se caracterizan por una mayor contratación irregular, mientras que las medianas y grandes que en general tienen a sus planteles registrados, suelen subcontratar/tercerizar trabajo en manos de empresas que sí contratan de forma irregular. Se estima que cerca de un $30 \%$ y un $40 \%$ de la fuerza de trabajo registrada está involucrada en distintas formas de subcontratación que además de una modalidad de bajar costos, constituye una forma de tener al colectivo laboral dividido (Basualdo y Morales, 2014).

Asimismo, se destaca la dificultad de detectar irregularidades en ciertas ramas de actividad en las cuales no alcanza la letra de las normas ni la inspección. Es el caso de algunas pequeñas empresas, el empleo rural, los talleres textiles y el servicio doméstico. Por tanto, la intervención requiere de estrategias complementarias más efectivas, como puede ser el protagonismo de los sindicatos y multas elevadas que tengan un efecto disuasivo para estas conductas.

\section{CAPACITACIÓN}

La incorporación de conocimiento y habilidades resulta de suma importancia para dotar al trabajador de mayores atractivos para el mundo de la demanda laboral, así como para la generación de autoemprendimientos. La formación permite incrementar en el corto plazo el capital humano proporcionándoles a las personas competencias para enfrentar el mercado laboral con mejores herramientas.

En Argentina $y$ en otros contextos en desarrollo, se reconoce la existencia de una oferta laboral que a pesar de detentar diversos niveles de calificación, persiste un volumen considerable de población trabajadora de baja calificación (sin secundario completo). En consecuencia, existen numerosas intervenciones con el propósito de favorecer la terminalidad educativa e incrementar el capital humano de la oferta laboral.

En las economías desarrolladas, los mecanismos de intermediación laboral tienden a ser las oficinas de empleo, en las cuales se atiende al desocupado, se inscribe en un registro y se informa acerca de las oportunidades laborales disponibles que podrían adecuarse a sus necesidades. No obstante, en las economías en desarrollo estos mecanismos constituyen alternativas poco frecuentes o insuficientemente desarrolladas y lo que suele prevalecer son programas de capacitación.

Los programas abocados a la terminalidad educativa o vinculados a capacitación en oficios (cursos, talleres, etc.) pueden resultar necesarios para incrementar la posibilidad de inserción. No obstante, la efectividad de este tipo de políticas, dependerá en gran medida de la posibilidad real de encontrar un empleo. Como menciona Velásquez (2005), la capacitación no genera empleo, aunque apunta a crear capacidades destinadas a mejorar la probabilidad de inserción productiva de la oferta de trabajo.

En estos casos, los incentivos a la capacitación cuando son combinados con programas de empleo directo o con subsidios a la contratación adicional de mano de obra, pueden mejorar la efectividad conjunta de las políticas aplicadas. Para ello, los programas 
de capacitación laboral debieran formar parte de estrategias más amplias de promoción a la inversión y al emprendimiento, que debido al aumento de la actividad económica genere más fuentes de empleo.

Existen numerosas evaluaciones de impacto en relación a los programas de capacitación implementados en diversos contextos. Algunos de ellos argumentan que el ciclo económico influye en la efectividad de los programas, siendo las capacitaciones algunas de las medidas más efectivas en aquellos períodos en que la economía está creciendo. Esto lleva a que, dado que típicamente los programas de capacitación se implementan en períodos de crisis económica, estos tiendan a mostrar malos o insuficientes resultados.

En los mercados laborales segmentados particularmente que presentan persistentes $y$ altas tasas de desempleo, pueden darse situaciones en las cuales una mayor capacitación sin una potencial (re)inserción efectiva al mercado laboral refuercen la frustración de las personas trabajadoras desempleadas y por tanto propicien el desaliento. Entre las falencias frecuentes en estos contextos es posible hacer referencia a la falta de adecuación en relación al tipo de capacitaciones (ramas de actividad, duración e intensidad), respecto de las características de los destinatarios de los programas (edad, localización geográfica, responsabilidades familiares, disponibilidad de viáticos, etc.) y particularmente, la correspondencia en relación a la demanda laboral local.

En términos generales, la política de capacitación $y$ formación profesional continua del MTEyss incluye acciones de terminalidad educativa, desarrollo y registro de normas de competencias laborales, certificación de personas trabajadoras según parámetros de competencias laborales normalizadas y actividades de formación profesional. Sin embargo, un informe publicado por el MTEyss en 2013 afirma que "el impacto positivo de la política tiene una magnitud moderada ya que el aumento de la probabilidad de inserción laboral producido por los cursos es relativamente bajo" y agrega "se pone en evidencia la necesidad de vincular y coordinar las políticas activas de empleo de manera de generar cambios significativos en las probabilidades de inserción de las personas al empleo" (мтеyss, 2013, p.152).

Si bien, son necesarias estas políticas ya que pueden existir ciertos sectores con demanda laboral insatisfecha asociada a la insuficiencia de credenciales, por ejemplo, técnicas, estos casos suelen constituir situaciones de demanda laboral insatisfecha marginales. Por otra parte, la posibilidad de seguir cursos de formación está en relación directa con el nivel de calificación anterior y son los más calificados los que suelen sacar mejor provecho de la formación (Neffa, 2011). Esta crítica refiere a que una parte significativa de quienes encuentran colocación gracias a estas capacitaciones corresponden al efecto del llamado "peso muerto", es decir, aquellos que de todas maneras se hubiesen colocado, aún en ausencia de capacitación (Samaniego, 2002), con lo cual en ocasiones se les ofrece apoyo $y$ posibilidades de empleo a quienes podrían conseguirlos solos.

Las prácticas de capacitación centran su accionar en el mejoramiento de las habilidades de la oferta de trabajo y constituyen instancias más efectivas cuando se acompañan de certificaciones que validan ese conocimiento adquirido. Sin embargo, en contextos en los cuales se crean escasos puestos de trabajo, puede suceder que estos aprendizajes no logren desembocar en una inserción laboral estable. Cuando esto ocurre, las personas trabajadoras suelen desalentarse en la permanencia de los cursos de capacitación o se ven forzadas a abandonar estas instancias de formación por la necesidad de realizar trabajos eventuales usualmente denominados "changas". Además, muchas veces cuando la capacitación ofrecida es de corta duración y su eficacia al estar ligada a la capacidad de respuesta de la economía no se logra, esta intervención se encuentra lejos de lograr un impacto significativo $y$ perdurable en el tiempo en la (re)inserción laboral estable y de calidad de las personas.

El grueso de las intervenciones citadas refieren al objetivo de la inserción laboral. Sin embargo, la práctica evidencia que en su aplicación tienden generalmente a centrar gran parte 
de sus esfuerzos en instancias de aprendizaje $y$ capacitación poco vinculadas a una inserción laboral efectiva.

\section{INTERMEDIACIÓN LABORAL}

La intermediación laboral se presenta como una de las modalidades de intervención más eficientes $y$ de mayor impacto en el objetivo de (re)inserción laboral. Ello, entre otras consideraciones, porque constituye además un servicio valorado en el mundo empresario ${ }^{30}$.

Cuando la intermediación laboral la lleva a cabo el Estado, se benefician diversos actores y los resultados pueden derivar en prácticas reales de inclusión laboral estable de segmentos más vulnerables. Estos segmentos conformados por personas de escasos recursos encuentran especialmente relevante la instancia de la intermediación laboral dado que al carecer de redes sociales y económicas que les permitan contactarse con potenciales empleadores, encuentran en esta un sistema eficiente que les permite disminuir los tiempos de búsqueda, sustituir el rol de las redes sociales y subsidiar los costos de transacción en que debe incurrir la persona que busca empleo (Castillo y Escárate, 2006).

En general, se ha logrado una lógica modernizadora de los servicios de intermediación laboral en la región latinoamericana, y Argentina no escapa a ella: a) introducción de sistemas de información; b) mayor participación del sector privado; c) modernización y expansión de la cobertura; $y$ d) descentralización

$30 \quad$ "Este tipo de programas tiene un alto potencial para mejorar la capacidad de adaptación de los mercados de trabajo y reducir el desempleo por carencia o asimetrías de información, para lo cual un diseño óptimo supone una estrecha vinculación con los servicios de capacitación laboral y con los sistemas de protección a los desempleados, en la medida en que las prestaciones monetarias, como las proporcionadas por los seguros de desempleo por ejemplo, son complementadas con servicios destinados a apoyar el proceso de reinserción en los mercados de trabajo" (Velásquez, 2005, p.26). La efectividad de las acciones de intermediación laboral a su vez dependerá de un seguimiento pos incorporación que le permita a la oficina de empleo acompañar al trabajador y guiar al empleador. de los esquemas al total del territorio (Samaniego, 2002).

Sin embargo, es frecuente que las empresas "desconfíen" de mecanismos como las Oficinas de Empleo para incorporar personal, es probable que falten "atractivos" que motiven a las empresas a recurrir a estos dispositivos. La Responsabilidad Social Corporativa (Rsc) puede ser una forma, pero fundamentalmente la eficiencia de la herramienta hará que sea considerada por los empleadores, así como, una buena estrategia de difusión y comunicación de los resultados de intermediación que derivaron en (re)inserción (por ejemplo, la presentación y el seguimiento de resultados de casos exitosos ${ }^{31}$ ). Mientras tanto, el grueso de las intervenciones por parte de estos organismos para el caso argentino suele acotar su tarea a la de "capacitar".

La información disponible y el relevamiento realizado a las empresas en este documento no dan muestras de que las Oficinas de Empleo dependientes del mтеyss, constituyan una referencia utilizada regularmente para los demandantes de trabajo. Diversas investigaciones de carácter cualitativo que describen la situación de los trabajadores en contextos de pobreza y vulnerabilidad, revelan la denuncia social en forma reiterada acerca de la ausencia de mecanismos eficientes y efectivos de intermediación laboral que actúen mediando las búsquedas de empleo en los sectores más pobres ${ }^{32}$.

31 Un análisis llevado a cabo por Neffa y Korinfeld (2006) acerca de las políticas de intermediación laboral para el caso argentino indica que en función del segmento de la fuerza de trabajo, es que operan diversas entidades de intermediación laboral. De este modo, las empresas consultoras de personas, universidades $y$ asociaciones profesionales se dedican fundamentalmente a sectores de profesionales altamente capacitados, trabajadores capacitados y especializados de nivel medio; las empresas de empleo temporario a profesionales de nivel medio y sin especialización, así como, técnicos y también algunas búsquedas para empleos en sectores poco o nada calificados; y en particular son las instituciones religiosas, así como, los servicios públicos de empleo los que cubren al segmento de menor calificación.

32 Pueden consultarse al respecto Sconfienza y Groisman (2013a) y Comas (2009). 
La intermediación laboral es una intervención de significativo valor dado que tiene el potencial de ser:

$\diamond \quad$ Un servicio que las empresas utilizan casi indefectiblemente.

$\diamond \quad$ Un nexo entre la población desocupada $y$ un servicio público concreto en el que se entrevista $y$ conoce a oferentes de empleo. Además, proporciona información de potenciales empleos, un sitio de referencia acerca de capacitaciones $y$ detalles sobre prestaciones de servicios de asistencia social $y$ otras de utilidad como viáticos $y$ vestimenta para asistir a entrevistas laborales.

$\diamond \quad$ Un medio a través del cual conocer y adentrarse en las características de los perfiles más buscados por los demandantes de empleo, orientando a los desocupados y desocupadas acerca de las capacitaciones y perfeccionamientos más afines a los requerimientos concretos de la demanda.

$\diamond \quad$ Un espacio en el que el cruce de información recabada por otros organismos públicos permite establecer un mapeo de la demanda laboral a nivel nacional (al menos de las entidades declaradas).

$\diamond \quad$ Una posibilidad de identificación de los perfiles de desocupados que puede permitir por ejemplo dar prioridad a los más vulnerables, estimados "menos empleables" (menos favorecidos, los que más lo necesitan), previniendo riesgos de que persista una situación de desempleo de larga duración.

$\diamond \quad$ Un espacio físico al cual las personas desempleadas pueden acudir y se les puede hacer un seguimiento de su situación ocupacional en el tiempo (téngase en cuenta que en ocasiones, algunos grupos más vulnerables no disponen de comunicación vía internet y/o telefonía móvil).

Una instancia de adecuación real en la cual el Estado puede "mediar" analizando los criterios de selección laboral, propiciando evitar la proliferación de prácticas discriminatorias (ya sea por características de edad o sector socioeconómico, como de solicitudes de perfiles con excesiva/inadecuada calificación en relación a la tarea a realizar).

En suma, las capacitaciones, los intentos de generación de empleo, la intermediación laboral y los subsidios al salario en general, si bien han tenido la intención de mejorar la incorporación de los segmentos más vulnerables al sistema productivo, entre otros, al momento no permiten identificar qué cantidad de población fue beneficiada. Complementariamente, no es posible conocer el seguimiento continuo $y$ personalizado de casos que permitan identificar la cantidad de personas involucradas que llegaron a obtener empleos registrados, estables $y$ seguros.

\section{CONCLUSIÓN}

Indiscutiblemente, el principal factor que impulsa la inclusión laboral, es el crecimiento sostenido y productivo de la economía, por consiguiente, la certidumbre económica y algunas políticas como el acceso al crédito. No obstante, la inclusión laboral independientemente del ciclo económico, presenta ciertas particularidades que inciden de forma directa en la oferta de empleo, "decidiendo" de alguna manera con base en ciertos criterios, cuáles segmentos son más proclives a ser incluidos y cuáles no.

Cuando los criterios de elegibilidad corresponden con las tareas a realizar, la oferta y la demanda de empleo se relacionan bajo una lógica de imparcialidad. Pero cuando esto no sucede, comienzan a operar lógicas de tendencia arbitrarias, es entonces cuando parte de la precariedad laboral en general y la exclusión del mercado de trabajo en particular, obedecen a la persistencia de prácticas "segmentadoras" provenientes de la demanda de empleo.

En consecuencia, algunas de las particularidades "segmentadoras" se dan cuando: a mayor nivel de calificación de la tarea y mayor tamaño de la unidad de producción, los medios de reclutamiento tienden a ser más estandarizados, mientras que por el contrario, en el caso de puestos de menor jerarquía y establecimientos más pequeños se utilizan mecanismos 
masivos e inespecíficos, siendo el caso de los referidos o contactos, "el" mecanismo de reclutamiento (cuando se trata de contrataciones en hogares particulares prácticamente con exclusividad). Por consiguiente, la inclusión laboral en estos casos va a estar sujeta a la disponibiliad de una amplia red de contactos, un significativo capital social que permita al trabajador "conectarse" con vacantes laborales.

Con el propósito de disminuir costos $y$ responsabilidades laborales, los encuadres normativos son muchas veces inadecuados a la relación laboral. Esto se hace visible generalmente de forma específica según el tamaño del establecimiento. Cuando se trata de pequeñas y medianas unidades de contratación, son frecuentes las relaciones de dependencia "encubierta" bajo la figura del monotributo; contratos en los cuales se subdeclaran horas/ categorías/salarios; $y$ el no registro. Cuando se trata de empresas de mayor tamaño, se suele incurrir en la utilización de contrataciones vía empresas intermediarias. Asimismo, la debilidad de representación sindical como en el caso del servicio doméstico afectan la posibilidad de empoderamiento $y$ el respeto por los derechos laborales en ciertos segmentos ocupados en hogares particulares.

Finalmente, la edad y el nivel educativo operan determinando la exclusión de oferta de trabajo. Con el fin de acotar el volumen de postulantes ante las vacantes laborales, las personas empleadoras (aprovechando el desajuste que existe en mercados como el argentino, en los que la oferta laboral es considerablemente superior a la demanda disponible, particularmente en los puestos de trabajo que en la práctica requieren de bajos niveles de calificación para su ejecución) tienden a imponer limitaciones inapropiadas como la edad o el nivel educativo.

Cuando suceden estas prácticas, se refuerza la segmentación y el dualismo del mercado laboral. En consecuencia, se requiere de la presencia de un Estado que pueda contrarrestar estas prácticas discriminatorias y orientar a la demanda de empleo para que adopten modalidades de trabajo que promuevan la equidad en el acceso al empleo. Sin embargo, por el momento, la mayoría de las intervenciones que se han llevado a cabo vía programas y planes, concentraron sus esfuerzos en consolidar esquemas de formación y capacitación. Cuando el entrenamiento es acompañado de estrategias de inclusión al trabajo efectivas, fortalece la valoración de estas instancias de aprendizaje. No obstante, en el caso argentino, una parte considerable de estas políticas carece de mecanismos de conexión efectivos con la demanda de empleo. No es posible observar la generación de cambios significativos en las probabilidades de inserción laboral de las personas a raíz de estos mecanismos.

En consecuencia, resulta meritorio preguntarse si en contextos de acotada demanda laboral y exceso de oferta de trabajadores de baja calificación, en los que además tienden a prevalecer umbrales de acceso al trabajo muchas veces arbitrarios, las políticas centradas en la capacitación no estarían reforzando la teoría del capital humano en la que se asigna a la persona desocupada la "responsabilidad" unívoca de su condición y se espera una inclusión por parte del mercado por el solo hecho de constituir fuerza de trabajo de mayor calificación. A partir de ello, se deduce que la segmentación si bien se vincula directamente con el nivel educativo, no es la causante de la exclusión, sino el mecanismo que opera como umbral en contextos de exceso de oferta laboral y escasez de demanda propiciándose prácticas precarizadoras de la fuerza de trabajo. La población empleadora tiende a ampliar sus pretensiones con el doble propósito de cubrir sus vacantes con perfiles más completos, inclusive innecesariamente más capacitados y a su vez, con el fin de acotar los procesos de selección a universos más restringidos.

Argentina muestra deficiencias de coordinación entre políticas que debieran velar por la equidad en el acceso al empleo y la erradicación de todo tipo de abuso laboral, ya sea en términos de encuadres normativos inadecuados, de no registro o de estigmas discriminatorios de la fuerza de trabajo. Se hace evidente la presencia de tímidos mecanismos de promoción del trabajo destinados a generar motivaciones por parte de personas empleadoras para que se 
les estimule a formar parte activa de la inclusión laboral de los segmentos más vulnerables. De esta forma, queda minimizada la labor que debería centralizar la intervención estatal como medio que por excelencia proporcione herramientas que potencien la (re)inserción laboral de los grupos más desfavorecidos.

Resulta necesario que se promueva desde el Estado, pero también desde el sector privado $y$ la sociedad civil, un ideario de responsabilidad en relación a la comunidad limitando la proliferación de dogmas discriminatorios en el acceso al empleo.

\section{REFERENCIAS BIBLIOGRÁFICAS}

Basañes, C. (2010). Análisis crítico sobre la relación entre la cooperativa de trabajo y sus asociados. Documento 69 Centro de Estudios de Sociología del Trabajo, FCEUBA, Argentina.

Basualdo, V. y Morales, D. (2014) La tercerización laboral. Orígenes, impacto y claves para su análisis en América Latina. Buenos Aires: Edición Siglo xxi.

Basualdo, V., Esponda, A., Gianibelli, G. y Morales, D. (2015). Tercerización y derechos laborales en la Argentina actual. Buenos Aires: Ed. La Página s.A.

Calero, A. (2012). Politicas para la formalización de los trabajadores por cuenta propia: el caso del Monotributo Social. Nota Técnica $N^{\circ} 63$ Empleo e Ingresos. (Informe Económico $\mathrm{N}^{\circ} 80$ ). Ministerio de Economía y Finanzas, Buenos Aires.

Castel, R. (1997). Las metamorfosis de la cuestión social. Una crónica del salariado. Editorial Paidós. Buenos Aires.

Castillo, R. y Escárate, J. (2006). Políticas activas de empleo $y$ desarrollo de una plataforma de intermediación laboral en Chile. Revista de Trabajo, 2 (2), pp.58.

Centro de Estudios de Investigaciones Laborales -cEIL. (2011). Políticas públicas de empleo iा. Empleo, desempleo \& políticas de empleo $N^{\circ} 7$, CEIL-Piette, conicet, Buenos Aires.

Centro de Investigación en Trabajo, Distribución y Sociedad -CITRAdis (2012).
El servicio doméstico en Argentina. Informe de situación 2004-2012 (Informes citradis), Buenos Aires.

Comas, G. (2009). Intermitencias: informalidad laboral y política social. Un estudio de caso en el GBa. $9^{\circ}$ Congreso Nacional de Estudios del Trabajo. Ponencia presentada. Buenos Aires. Recuperado de http://www.aset.org.ar/congresos/9/ Ponencias/p5_Comas.pdf

Decreto $N^{\circ}$ 1694/2006, Argentina.

Escarabajal, A. y Rus, I. (2013). Percepciones psicosociales de la exclusión que determinan la inclusión socio laboral. Revista de Ciencias Sociales, XIX (1), 13-21.

Goldin, A. (2008). Normas laborales y mercado de trabajo argentino: seguridad y flexibilidad. Revista de la CEPAL. División macroeconomía del desarrollo (74).

Groisman, F. (2010). La persistencia de la segregación residencial socioeconómica en Argentina. Estudios demográficos $y$ urbanos, 25 (2), 455.

Groisman, F. y Beccaria, L. (2008). Informalidad y pobreza en Argentina. Investigación Económica, 67 (26), 135169.

Groisman, F. y Beccaria, L. (2009). Argentina Desigual. Buenos Aires: Edición Prometeo.

Groisman, F.; Beccaria, L.; Maurizio, R. y Gonzalez, M. (2006). La sobreeducación en la provincia de Buenos Aires. Un análisis exploratorio. Universidad Nacional General Sarmiento, Buenos Aires.

Instituto Nacional contra la Discriminación, la Xenofobia y el Racismo -INADI (2014). Mapa nacional de la discriminación. Instituto Nacional contra la Discriminación, la Xenofobia y el Racismo, Buenos Aires.

Instituto Nacional de Estadística y Censos -INDEc (2003). La nueva Encuesta Permanente de Hogares de Argentina, s.l.: s.n.

Ley $\mathrm{N}^{\circ}$ 20.744. Ley de Contrato de Trabajo. Boletín Oficial República Argentina. 
Ley $\mathrm{N}^{\circ}$ 22.250. Régimen Legal de Trabajo para el Personal de la Industria de la Construcción. Boletín Oficial República Argentina.

Ley $\mathrm{N}^{\circ}$ 25.164. Regulación de Empleo Público Nacional. Boletín Oficial República Argentina.

Ley $\mathrm{N}^{\circ}$ 26.727. Ley de Trabajo Agrario. Boletín Oficial República Argentina.

Ley $\mathrm{N}^{\circ}$ 26.844. Régimen Especial de Contrato de Trabajo para el Personal de Casas Particulares. Boletín Oficial República Argentina.

Magdoff, F. y Magdoff, H. (2004). Disposable Workers Today's Reserve Army of Labor. Monthly review. New York.

Ministerio de Trabajo, Empleo y Seguridad Social -mтеyss- y Organización Internacional del Trabajo -oiт-. (2007). Los trabajadores independientes y la seguridad social. Ministerio de Trabajo, Empleo y Seguridad Social, Argentina.

Ministerio de Trabajo, Empleo y Seguridad Social -mтeyss. (2010) Programa de Recuperación Productiva. Memoria 2003-2010. Buenos Aires.

Ministerio de Trabajo, Empleo y Seguridad Social -мтеyss. (2012). Boletín de estadísticas laborales. Revista de Trabajo, 8 (10), pp. 308.

Ministerio de Trabajo, Empleo y Seguridad Social -mтEyss. (2013). Trabajo, ocupación y empleo. Investigaciones 2013. Estudios sobre multinacionales y evaluación de políticas públicas. Serie estudios $N^{\circ} 12$, pp. 152.

Neffa J.; Oliveri M. L.; Persia J. y Trucco, P. (2010). La crisis de la relación salarial: naturaleza y significado de la informalidad, los trabajos/empleos precarios y los no registrados. Empleo, desempleo \& políticas de empleo. pp.34. CEIL-PIETTE, CONICET.

Neffa, J. C. y Korinfeld, S. (2006). Los intermediarios del mercado de trabajo. Situación en un momento de crisis. Revista de Trabajo, 2 (2), pp. 46.

Neffa, J.C. (2011).Políticas de empleo: dimensiones conceptuales $y$ diversos componentes. Empleo, desempleo y políticas de empleo. CEIL-PIETTE, CONICET.

Orellano, M. (2005). Trabajo, desocupación y suicidio. Efectos psicosociales del desempleo. Buenos Aires: Lumen Humanitas.

Organización Internacional del Trabajo -отт. (2002). Recomendación 193 sobre la promoción de las cooperativas. Ginebra: orT.

Organización Internacional del Trabajo -orT-. (2008). Resolución sobre la actualización de la Clasificación Internacional Uniforme de Ocupaciones. s.l., s.n. Ginebra: oIT.

Paugam, S. (1997). Les salariés de la precarieté, Les nouvelles formes de l'intégration professionnelle. Paris: PuF.

Piore, M. J. (1983). Notas para una teoría de la estratificación del mercado de trabajo, en L. Toharia, El mercado de trabajo: Teorías y aplicaciones. Madrid: Alianza.

Piore, M. J. (1978). Dualism in the Labor Market: A Response to Uncertainty and Flux. The Case of France. Revue économique, 29 (1), 26-48.

Samaniego, N. (2002). Las políticas de mercado de trabajo y su evaluación en América Latina. Macroeconomía del desarrollo (19), pp. 20.

Sconfienza, M. E. (2012). Vulnerabilidad laboral en la Ciudad de Buenos Aires: una mirada a las personas en situación de indigencia. (Tesis de Maestría). Facultad Latinoamericana de Ciencias Sociales, Andes, Ecuador.

Sconfienza, M. E. y Groisman, F. (2013b). El servicio doméstico en Argentina. Particularidades y desafíos de un sector relegado (2004-2012). Avances de Investigación, (14), pp. 171.

Sconfienza, M. E. y Groisman F. (2014). El servicio doméstico en Argentina. Particularidades y desafíos de un sector relegado (2004-2012). Revista Carta Económica Regional del Centro Universitario de Ciencias Económico Administrativas. Universidad de Guadalajara, México. 
Sconfienza, M. E. y Groisman, F. (2015). Una aproximación al desaliento laboral en Argentina. Cuadernos del Centro de Estudios del Desarrollo, (87), pp. 98.

Sconfienza, M. E. y Groisman, F. (2013a). "Indigentes urbanos: entre la estigmatización y la exclusión social en la ciudad de Buenos Aires" en Revista de Estudios Sociales, N47, Universidad de los Andes, Colombia, pp. 92-106.

Tefft, N. (2011). Insights on unemployment, unemployment insurance, and mental health. Journal of Health Economics 30, 258-264.

Velásquez, M. (2005). La protección frente al desempleo en América Latina. CEPAL, (166).

Vilaseca, G., (2007). El quiebre del proyecto laboral y su repercusión en la vida del varón. Reflexiones sobre masculinidades $y$ empleo. Universidad Nacional Autónoma de México.

Fecha de ingreso: 21/11/2016

Fecha de aprobación: 26/06/2017 
